\title{
Cidadania global em aulas de português como língua adicional
}

\author{
Kleber Aparecido da Silva ${ }^{1}$ \\ Universidade de Brasília (UnB), Brasília, DF, Brasil \\ Eduardo Viana da Silva² \\ University of Washington (UW), Seattle, WA, EUA
}

\begin{abstract}
Apresentação
Este dossiê apresenta uma série de estudos que articulam o ensino do português como língua adicional (PLA) sob o prisma da cidadania global, incluindo estudos teóricos e pedagógicos que fomentam uma abordagem crítica e humanitária em aulas de PLA. Os autores apresentam perspectivas teóricas e aplicações educacionais tendo como referência principal os cursos de português no Brasil, além de cursos na Ásia, em Portugal, no Canadá e na América Central. Consideram-se amplamente os contextos locais e globais dos estudos aqui apresentados. Temas como a globalização e a comunicação intercultural são analisados pelos autores a partir do que Paulo Freire determina como "o educar para humanizar". Seguindo a proposta freiriana, observa-se ao longo deste dossiê teorias que apresentam os conceitos de cidadania global e pedagogia crítica, incentivando-se um diálogo produtivo, e por vezes desafiador, nas aulas de português como língua adicional (SILVA; SANTOS, 2013; FREIRE, 1987, 1997).
\end{abstract}

\footnotetext{
${ }^{1}$ Kleber Aparecido da Silva possui Pós-Doutorado em Linguística Aplicada pela UNICAMP; em Linguística Aplicada e Estudos da Linguagem pela PUC-SP; em Linguística pela Universidade Federal de Santa Catarina (UFSC). Doutor em Estudos Linguísticos pela UNESP (São José do Rio Preto). Mestre em Linguística Aplicada pela UNICAMP. É professor associado 1 do Departamento de Linguística, Português e Línguas Clássicas e do Programa de PósGraduação em Linguística do Instituto de Letras da Universidade de Brasília (UnB), do Programa de PósGraduação em Letras: Cultura, Educação e Linguagens da Universidade Estadual do Sudoeste da Bahia e do Programa de Pós-Graduação em Letras da Universidade Federal de Tocantins - Campus de Porto Nacional. Coordenador do Grupo de Estudos Críticos e Avançados em Linguagens (GECAL/CNPq-UnB). Orcid: https://orcid.org/0000-0002-7815-7767 E-mail: kleberunicamp@yahoo.com.br

${ }^{2}$ Eduardo Viana da Silva possui Doutorado em Estudos Hispanos (Literatura Brasileira) com especialização em Linguística Aplicada pela Universidade da Califórnia, em Santa Bárbara (UCSB), nos Estados Unidos. Mestre em Literatura Luso-Brasileira pela Brigham Young University (BYU), nos Estados Unidos. É professor associado de ensino na Universidade de Washington, em Seattle, nos Estados Unidos, onde coordena o Programa de Português. Suas áreas de interesse incluem a pedagogia crítica, linguística aplicada, literatura luso-brasileira,

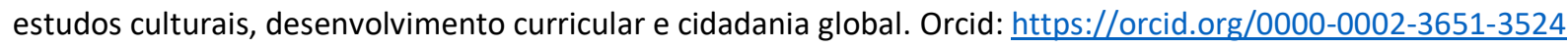
E-mail: evsilva@uw.edu
} 
O objetivo central deste dossiê é o de apresentar um marco teórico-pedagógico que vai além do mero ensino de diferenças sócio-culturais, tais como as que se veem frequentemente em livros textos de português, mas propor também a formação de cidadãos globais e pensadores críticos. Os artigos aqui apresentados incentivam a implementação de técnicas de ensino que promovam um pensamento independente, bem informado e crítico entre os estudantes e professoras/professores de português. Tal orientação pedagógica baseia-se em conceitos de descolonização global e em dimensões de identidade nacional, política, ética e cultural, que dada a natureza das aulas de línguas e as limitações linguísticas dos estudantes, são muitas vezes analisadas e articuladas a partir de produtos culturais, sem necessariamente promover uma discussão mais aprofundada do significado de tais produtos.

Este dossiê abre com dois artigos que tratam do ensino de PLA e de sua dimensão global durante a pandemia do COVID-19. Rosana Helena Nunes e Kleber Aparecido da Silva propõem uma pedagogia humanizadora para o ensino de PLA durante o COVID-19. Os autores oferecem um panorama do português como uma língua internacional, apresentando uma discussão teórica sobre as políticas linguísticas em Pennycook (1998; 1999; 2001) e Calvet (2007), entre outros estudiosos, e uma discussão sobre a linguagem como formação humana e emancipatória do indivíduo. Já o segundo artigo, de autoria de Hanzi Zhang, analisa a evolução multidimensional das competências interculturais através da interação virtual entre 27 estudantes chineses de PLA e 27 estudantes portugueses. A ênfase de seu estudo é nas relações interpessoais entre os estudantes chineses e portugueses durante a crise do COVID19.

Considerando-se as perspectivas local e global, os próximos artigos tratam do português como língua de acolhimento (PLAc) no contexto de imigrantes e refugiados no Brasil. Luiza Silva de Andrade discute a conexão entre a linguística aplicada e a antropologia. A autora analisa os conceitos de não-lugar e de lugar a partir no contexto de supermodernidade (Marc Augé, 1995). No processo de transformação dos não-lugares em lugares, Luiza Silva de Andrade argumenta em favor da inclusão dos estudantes migrantes em suas comunidades e da importância de se dar agência aos estudantes de PLAc, como, por exemplo, por meio das narrativas de sobrevivência.

Por sua vez, o estudo de Marcus Vinícius da Silva e Cora Elena Gonzalo Zambrano reflete sobre a formação de professores para os programas de PLAc com estudantes em situação de imigração e refúgio no estado de Roraima. Os autores propõem uma análise do contexto global ao local, enfatizando a importância da descolonização das salas de PLAc e demonstrando ações políticas formativas pontuais desenvolvidas pelo Programa de PósGraduação em Letras da Universidade Federal de Roraima.

Ainda sobre o tema de PLAc, Lovani Volmer, Pietra da Roos e Rosemari Lorenz Martins discutem as experiências de acadêmicos de licenciatura em Letras da Universidade Feevale em oficinas de português para migrantes e refugiados na cidade de Novo Hamburgo, no Rio Grande do Sul. As autoras descrevem as iniciativas pedagógicas e as oficinas de ações educativas voltadas para a garantia dos direitos humanos, visando a integração dos migrantes em sua comunidade e o exercício de sua cidadania. 
O cunho pluricêntrico de PLA e as questões de identidade são os temas centrais dos artigos seguintes. Gabriel Nascimento e Maria D'Ajuda Alomba Ribeiro apresentam um estudo de caso, no qual se discute a questão identitária de um professor de português estrangeiro. Os autores defendem a língua como direito, como o espaço no qual os sujeitos podem existir legitimamente. No que tange à legitimidade, à cidadania global e à sensibilidade local, Isabel Cristina Michelan de Azevedo, Ricardo Nascimento Abreu e Raquel Meister Ko. Freitag argumentam em seu artigo que o português brasileiro e suas variantes correm o risco de serem sub-representados e estereotipados. Os autores defendem a necessidade de desenvolvimento de uma consciência crítica intercultural. Seguindo esta mesma linha de raciocínio, Luciana Graça e Anabela Rato propõem atividades didáticas que demonstram a diversidade linguística e cultural do mundo lusófono, com o objetivo de oferecer uma abordagem pluricêntrica para as aulas de PLA, promovendo assim a cidadania global. As autoras baseiam-se em experiências prévias com o ensino de PLA através de projetos no Canadá.

Considerando-se as perspectivas do português para fins específicos, Luísa Zanini Vargas apresenta um relato de um projeto sobre a capoeira realizado em uma escola na Martinica, território insular ultramarino francês, e tem como objetivo esmiuçar cada etapa dessa experiência e analisar seus efeitos sobre o corpo discente. $O$ projeto relatado neste artigo, que durou cerca de dois meses, foi embasado em uma perspectiva comunicativa, acional e intercultural, e contou com o aporte teórico dessas áreas no âmbito do ensino de português enquanto língua estrangeira (PLE). A análise realizada pela autora buscou englobar o contexto sociocultural da escola e do público e os objetivos linguísticos e sociais propostos pelos docentes, em prol de uma formação à cidadania.

Elisa Marchioro Stumpf tem por foco no seu artigo o português acadêmico em aulas de PLA. Para tal intento, a pesquisadora apresenta e discute uma proposta de um curso de leitura e produção de textos acadêmicos em português como língua adicional para pósgraduandos estrangeiros em uma universidade brasileira. O quadro teórico que guiou o planejamento do curso vem do modelo de letramentos acadêmicos, que destaca aspectos sociais das práticas de leitura e escrita, além de questões de poder e conhecimento, bem como as identidades dos alunos e práticas de criação de sentido. Considerando a possibilidade de utilizar o modelo para o planejamento de cursos de escrita (LILLIS, 2003), a autora examinou como este planejamento pode ser útil para expandir o ensino para além do texto. Mostrando como os princípios se materializaram no planejamento e execução do curso, discutimos suas possibilidades e limitações para o contexto.

O ensino de português como língua adicional em contexto universitário, a partir de uma pedagogia crítica intercultural é o foco do artigo de Cristina Lopes Perna e Heloísa Orsi Koch Delgado. As autoras realizaram um trabalho de cunho teórico-pedagógico e discorrem sobre a relevância da língua portuguesa no Brasil e no mundo, por meio de dados estatísticos, enfatizando o seu papel como língua adicional, como ponto de intercâmbio cultural e comercial, e de permuta econômica. Tratam, num segundo momento, de conceitos sobre a educação para a cidadania global, e apresentam aquele utilizado na prática docente das 
autoras em contexto universitário, qual seja, o do incentivo à aprendizagem da convivência e cooperação local e global. Por último, discorrem sobre a disciplina de português como língua adicional para alunos internacionais cursando pós-graduação em uma instituição de ensino superior do sul do país, ressaltando ações que buscam contribuir para o intercâmbio do pensamento científico crítico inserido em um ambiente plurilinguístico e multicultural.

E no fechamento deste dossiê temos dois artigos que tratam especificamente do exame do Certificado de Proficiência em Língua Portuguesa para Estrangeiros (Celpe-Bras). Michele Saraiva Carilo analisa a influência do teste de proficiência Celpe-Bras nos programas curriculares de português, argumentado em favor de pedagogias críticas e interculturais. Para tal intento, apresenta-se um estudo sobre os processos de desenvolvimento e implementação curricular para cursos de português como língua adicional no contexto do Programa de Estudante-Convênio de Graduação (PEC-G). A autora teve a seguinte questão norteadora: o que formata currículos de PLA no contexto do PEC-G? Os resultados revelaram que o CelpeBras tem servido como orientação para desenvolvimento e/ou implementação curricular para cursos de PLA no contexto do PEC-G. Enquanto as contribuições das abordagens comunicativas e com base em tarefas para a área da educação de línguas adicionais são reconhecidas, pedagogias críticas e interculturais são introduzidas para propor uma atualização teórico-pedagógica no campo do PLA - especialmente para propósitos curriculares.

Mahulikplimi Obed Brice Agossa finaliza o dossiê com uma resenha crítica do documento-base do exame Celpe-Bras e visa apresentar respostas para as seguintes perguntas: o que este recém-publicado documento-base tem de diferente dos demais documentos? Quem são os/as responsáveis pelo conteúdo? Qual a importância do documento para os/as usuário(a)s do exame?

Acreditamos que todos os artigos presentes neste dossiê, conforme enfatizado na introdução deste texto, apresentam um marco teórico-pedagógico que vai além do mero ensino de diferenças sócio-culturais, mas propõem também a formação de cidadãos globais e pensadores críticos (FREIRE, 1987, 1997), a partir da compreensão dos fenômenos investigados e contribuindo assim para o desenvolvimento do conhecimento científico, teórico e pedagógico. Por isso, convidamos o leitor a refletir sobre os trabalhos neste dossiê e a analisar como se (re)constrói uma cidadania global em aulas de português como língua adicional.

\section{Referências}

FREIRE, P. Pedagogia do oprimido. Rio de Janeiro: Paz e Terra, 1987.

FREIRE, P. Pedagogia da autonomia. São Paulo: Paz e Terra, 1997.

SILVA, K. A.; SANTOS, D. T. (Orgs) Português como língua (inter)nacional: faces e interfaces. Campinas: Pontes Editores, 2013. 